Open Access

\title{
Expression patterns of TRa and CRABPII genes in Chinese cashmere goat skin during prenatal development
}

\author{
Tao Zhong ${ }^{1+}$, Wei Zhao ${ }^{1+}$, Zhongqiang Zhou' ${ }^{1}$ Li Li ${ }^{1}$, Linjie Wang ${ }^{1}$, Hua $\mathrm{Li}^{2^{*}}$ and Hongping Zhang ${ }^{1 *}$
}

\begin{abstract}
Background: The physiologic characteristics of the cashmere trait and many of the differentially expressed genes relevant to hair cycling have been extensively studied, whereas genes involved in the prenatal development of hair follicles have been poorly investigated in cashmere goats. The aim of this study, therefore, was to quantify the time-course changes in the expressions of TRa and CRABPIl genes in the fetal skin of Chinese cashmere goats at the multiple embryonic days (E70, E75, E80, E90, E100, E120 and E130) using real-time quantitative PCR (RT-qPCR).

Results: RT-qPCR showed that TRa was expressed at E70 with relatively high level and then slightly decreased (E75, E80, and E90). The highest expression of TRa mRNA was revealed at E130 $(P>0.05)$. The expression pattern of CRABPI/ mRNA showed an 'up-down-up' trend, which revealed a significantly highest expression at E75 $(P<0.05)$ and was down-regulated during E80 to E120 $(P<0.05)$ and mildly increased at E130, subsequently.

Conclusion: This study demonstrated that TRa and CRABPII genes expressed in different levels during prenatal development of cashmere. The present study will be helpful to provide the comprehensive understanding of $T R a$ and CRABPIl genes expressions during cashmere formation and lay the ground for further studies on their roles in regulation of cashmere growth in goats.
\end{abstract}

Keywords: Cashmere goat, TRa, CRABPII, Skin, Expression

\section{Background}

The Inner Mongolian cashmere goat is a Chinese indigenous breed characterized as a double-coated species. The outer coat consists of coarse guard hairs and the undercoat is the soft and precious cashmere. Two kinds of hair follicles which known as primary hair follicles and secondary hair follicles existed in the skin of the Inner Mongolian cashmere goat. Cashmere, which is derived from the secondary hair follicles, has smaller diameters than wool fibers produced by the primary hair follicles. Primary hair follicles and secondary hair follicles form at different periods and play different roles in the development of hair. In mice, the primary hair follicles arose in utero from

\footnotetext{
* Correspondence: 121183050@qq.com; zhp@sicau.edu.cn

${ }^{\dagger}$ Equal contributors

${ }^{2}$ School of Life Science, Foshan University, Foshan 528000, P. R. China

${ }^{1}$ Farm Animal Genetic Resources Exploration and Innovation Key Laboratory of Sichuan Province, College of Animal Science and Technology, Sichuan Agricultural University, Chengdu, Sichuan 611130, P. R. China
}

embryonic day (E) 12.5 and the secondary follicles started to develop until E17 [1, 2]. In goat embryos, the precursor primary follicles were observed in head, neck, shoulder, and belly at E45. The hair follicles gradually formed during $55 \mathrm{E}$ to $65 \mathrm{E}$ and developed into the mature primary follicles at E135 [3]. The morphogenesis and development of the secondary follicles were similar to those of the primary follicles. The secondary follicles grew from E65 to E75 and then extended to skin surface. The complete structure of the secondary follicle was formed at E135 in the embryos of Chinese cashmere goats [4]. Furthermore, the periodic growth of the secondary follicles also presented in a breed-specific manner [5]. All primary follicles but few secondary follicles were mature at birth and the number of secondary follicles increased 10-fold in the 57 days after birth. The number of primary follicles showed a tendency to decline between 57 and 107 days of age in Australian cashmere goats [6]. Like the hair follicle cycling in other mammals, the growth 
of cashmere in goats was also tightly programmed by the three synchronized interchanging stages, anagen (growth phase), catagen (regression phase) and telogen (resting phase) throughout postnatal life [7, 8].

Some genes involved in the growth and development of hair follicles in cashmere goats have been identified, such as KAPs [9, 10], BMP [11], Prolactin [12], and Keratin $[13,14]$. Furthermore, in mammals, the thyroid hormones $(\mathrm{TH})$ have multi-functions in many important physiological processes including the normal growth, development, differentiation and metabolism. Recently, new insights into $\mathrm{TH}$ biological function have been obtained from animal studies involving in epidermis, dermis and hair cycling including anagen prolongation and stimulation of both hair matrix keratinocyte proliferation and hair pigmentation $[15,16]$. The metabolism of $\mathrm{TH}$ is related to deiodinase, which is also regulated cashmere growth by altering its activity in skin tissue $[17,18]$. $\mathrm{TH}$ action could be mediated through the thyroid hormone receptor (TR), which is part of the nuclear hormone receptor superfamily and bound to $\mathrm{TH}$ in three patterns identified in skin $[19,20]$. TR interacts with the hairless gene product, a transcription factor required for hair growth. TR has been detected in epidermal keratinocytes, skin fibroblasts and a number of cell types that made up the hair follicles. In addition, the retinoic acid (RA) is essential for the development and maintenance of hair cycling [21]. The cellular RA-binding protein type II (CRABPII) is involved in RA synthesis pathway, which could shuttle RA to its receptor in nucleus and increase its transcriptional efficiency [22]. Therefore, the dynamic expression of CRABPII mRNA could affect the concentration of RA, which acts on the formation of cashmere though regulating sebaceous gland. During hair cycle, the expression pattern of the RA synthesis and signaling including Crbp, Dhrs9, Aldh1a1, Aldh1a2, Aldh1a3 and Crabp2 defined in rodents only [23].

Based on the genetic studies in humans and rodents, TR $\alpha$ and CRABPII acted important roles in driving the progression of the hair cycle. We postulate that these two genes might have functions during cashmere formation in goat. So in this study, we described the characteristics of $T R \alpha$ and CRABPII genes in the Inner Mongolian cashmere goat and identified their expression patterns in skin tissue during the middle late embryonic stages (E70 to E130).

\section{Materials and methods}

\section{Animal and skin tissue preparation}

The Inner Mongolia cashmere goat is a traditional outstanding breed, which is famous for its excellent cashmere performance and strong adaptation to the semi-desert and desert steppes. The tested individuals were selected from the Aerbasi White Cashmere Goat Breeding Farm in Inner Mongolia Province, China. Twenty-one embryos (three samples at each stage) were randomly collected and any lineage was avoided during the sampling process. Skin samples (approximately $1 \mathrm{~cm}^{2}$ for each individual) were collected from right mid-side of embryos at seven different embryonic days (E70, E75, E80, E90, E100, E120 and E130). Tissue was frozen in liquid nitrogen and stored at $-80{ }^{\circ} \mathrm{C}$

Table 1 The RT-PCR and qRT-PCR primers used in this study

\begin{tabular}{|c|c|c|c|}
\hline Primer Name & Sequence $\left(5^{\prime}-3^{\prime}\right)$ & Fragment size (bp) & T.M. $\left({ }^{\circ} \mathrm{C}\right)$ \\
\hline \multicolumn{4}{|c|}{ Cloning primers } \\
\hline TRa-1 F & CCTGGATGGAATTGAAGTGA & 799 & 62.0 \\
\hline$T R a-1 R$ & GACATGATCTCCATGCAGC & & \\
\hline TRa-2 F & AGGCCTTCAGCGAGTTTAC & 652 & 59.0 \\
\hline$T R a-2 R$ & CCTTCTCTCCAGGCTCCTC & & \\
\hline CRABPII-1 F & CAGTGCTCCAGTGGAAAGA & 563 & 56.5 \\
\hline CRABPII-1R & CCAGAAGTGATTGGGTGAG & & \\
\hline \multicolumn{4}{|c|}{ Real-time $P C R$ primers } \\
\hline TRa-3 F & TTACCTGGACAAAGACGAGC & 113 & 57.4 \\
\hline$T R a-3 R$ & TCTGGATTGTGCGGCGAAAG & & \\
\hline CRABPII-2 F & ACATCAAAACCTCCACCACC & 111 & 56.5 \\
\hline CRABPII-2R & CCCATTTCACCAGGCTCTTA & & \\
\hline ACTB-F & CCTGCGGCATTCACGAAACTAC & 87 & 58.5 \\
\hline ACTB-R & ACAGCACCGTGTTGGCGTAGAG & & \\
\hline GAPDH-F & GCA AGTTCCACGGCACAG & 249 & 59.0 \\
\hline GAPDH-R & GGT TCACGCCCATCACAA & & \\
\hline TOP2B-F & GTGTGGAGCCTGAGTGGTATA & 137 & 59.0 \\
\hline TOP2B-R & AAGCATTCGCCTGACATTGTT & & \\
\hline
\end{tabular}


(a)

Mouse NP 835161 Rat_NP_o 01017960 Human_N NP_955366 Pig NP 999355

Sheep_ND_001094389 Goat_TRa

Cattle XP 005220791

Chicken_N $\bar{P}$ _990644

Consensus

Mouse_NP_835161 Rat_NP_O01017960 Human NP 955366

Pig N $\bar{P} 9 \overline{9} 9355$

Sheep_NP_001094389 Goat TRa

Cattle XP 005220791 Chicken_NP_990644 Consensus

Mouse_NP_835161 Rat $\mathrm{NP} \quad 0 \overline{0} 1017960$ Human NP 955366 Pig_N $\bar{P}$ 9 $\overline{9} 9355$ Sheep_NP_001094389 Goat_TRa

Cattle_XP_005220791 Chicken_N $\bar{P}$ _990644 Consensus

Mouse_NP 835161 Rat NP 001017960 Humàn $\bar{N} P$ 955366 Pig NP $9 \overline{9} 9355$

Sheep NP 001094389 Goat TRa Chicken_NP_990644

\section{Mouse NP 835161} Rat_NP_0 01017960 Human_N NP_955366 Pig NP $9 \overline{99} 9355$ Goat_TRa Consensus

\section{(b)}

Sheep_XP_004002676 Goat_CRABBPI Pig NP 001157981 Cattle NP 001008670 Human_N ${ }^{-}$_o 01869 Mouse_NP_031785 Rat NP $0 \overline{5} 8940$ Consensus

Sheep XP 004002676 Goat CRABBII Pig_NP_001157981 Cattle NP 001008670 Human_NP_o01869 Mouse NP 031785 Rat NP 058940 Consensus
Cattle_XP_005220791 Consensus

Sheep_N NP_001094389

Cattle XP 005220791

Chicken N $\bar{P} 990644$
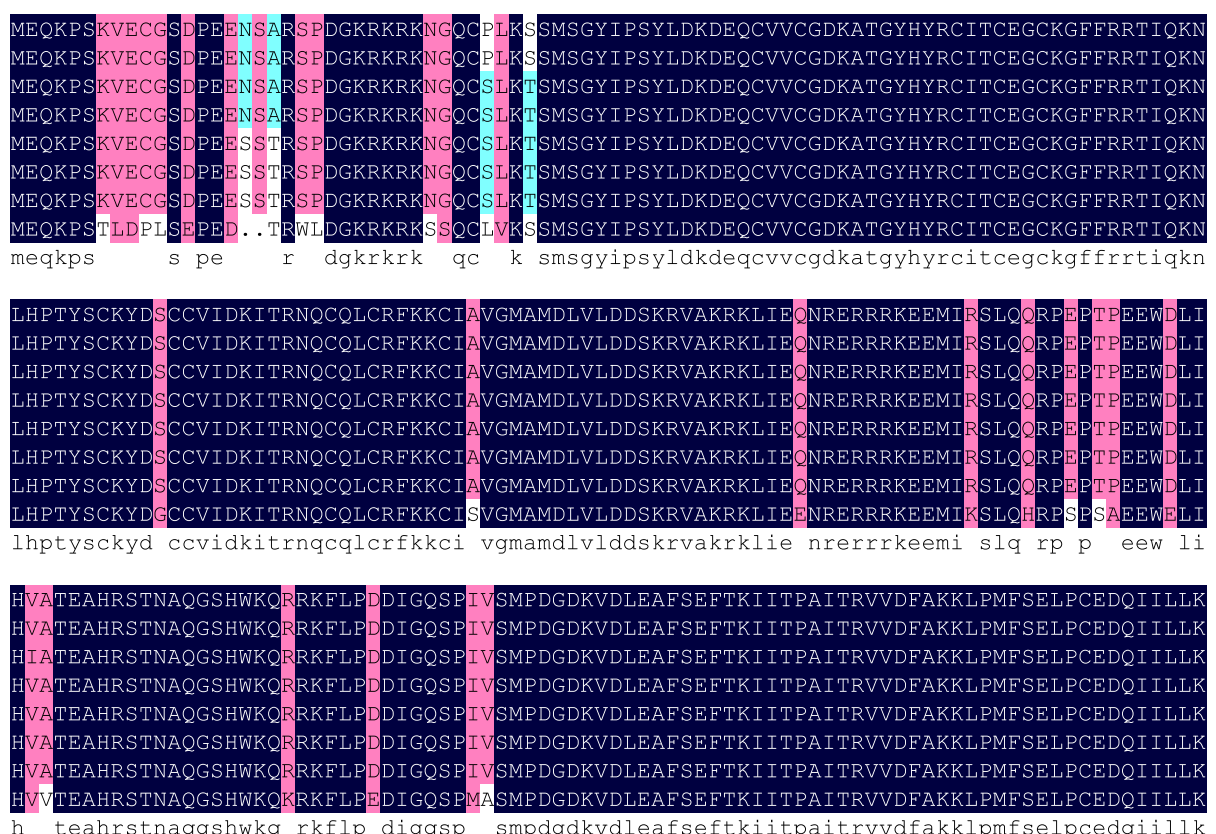

smpdgdkvdleafseftkiitpaitrvvdfakklpmfselpcedqiillk
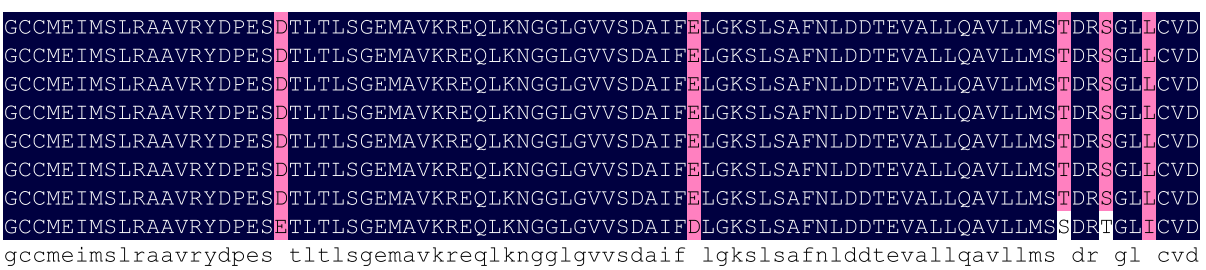

336

336

336

336

336

336

336

334

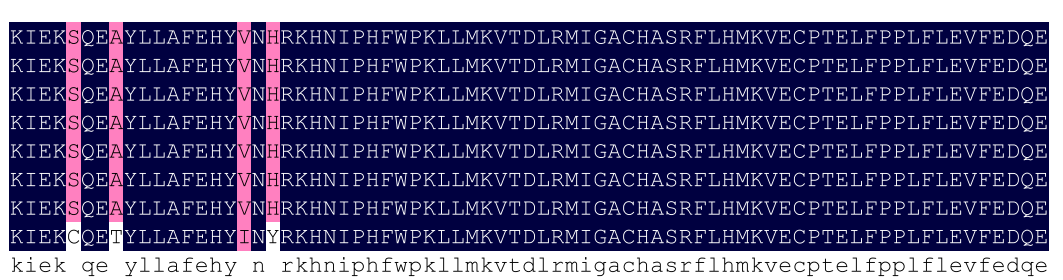

409

409

409

409

409

409

409

407
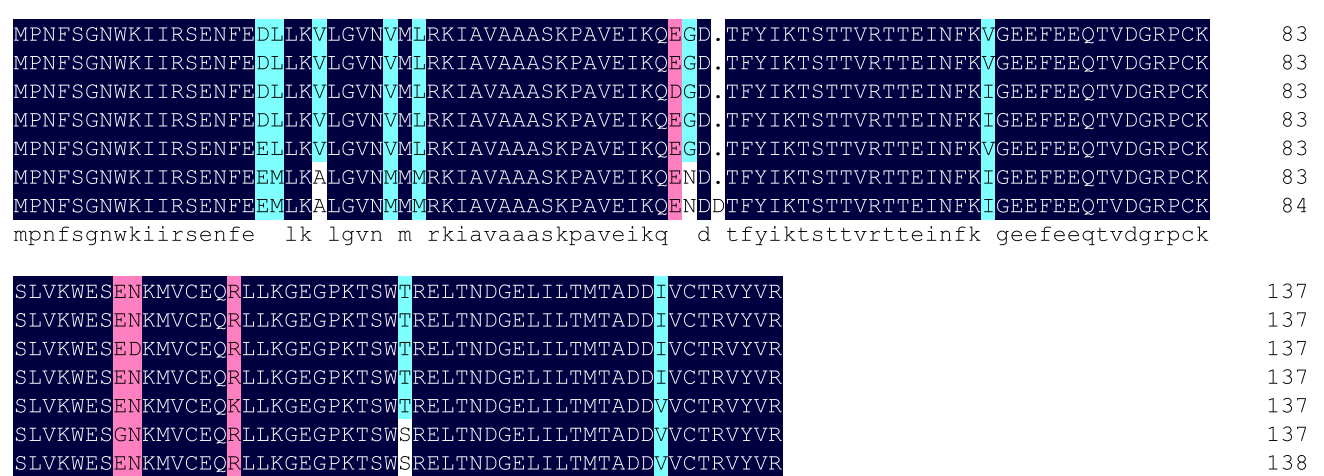

Fig. 1 Alignment of the TRa (a) and CRABPIl (b) amino acid sequences

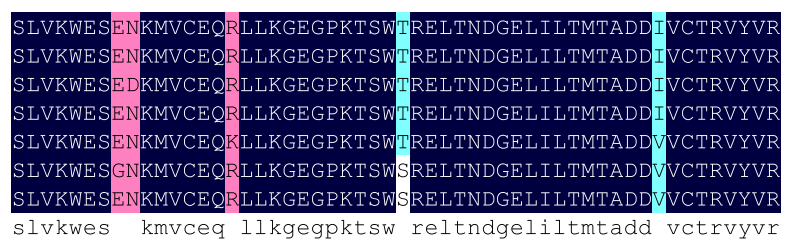



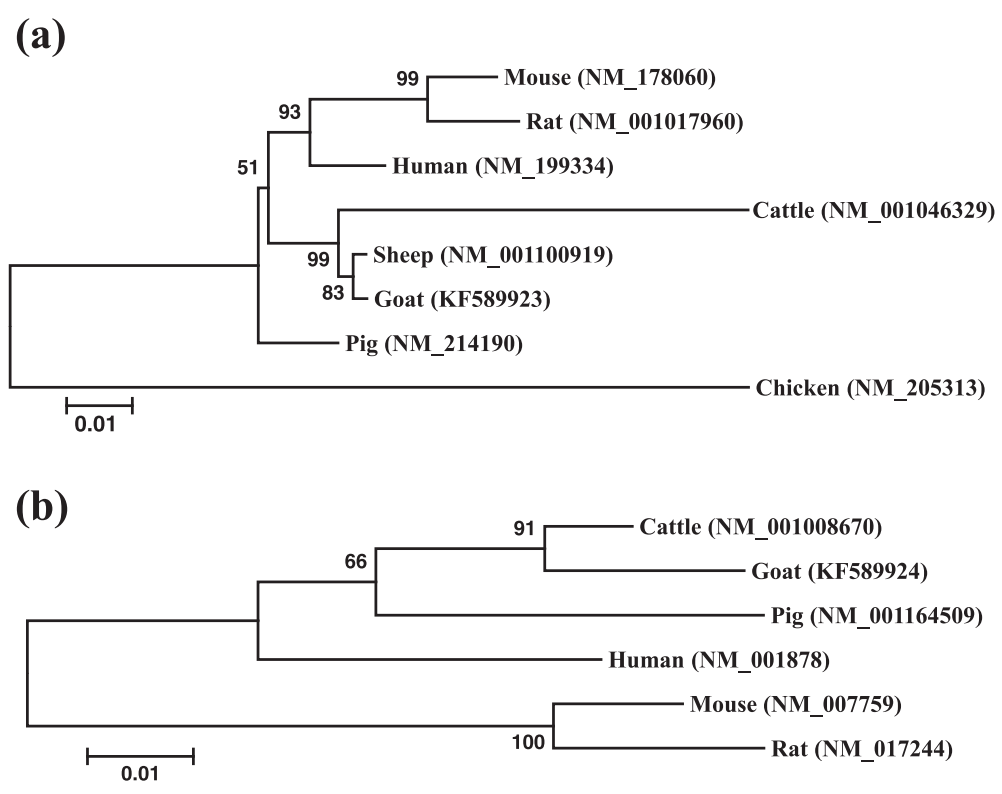

Fig. 2 The phylogenetic trees constructed by coding sequences of TRa (a) and CRABPII (b) based on the Neighbor-Joining method

for further analysis. All the experimental procedures for this experiment were conducted under a protocol approved by the Institutional Animal Care and Use Committee in the College of Animal Science and Technology, Sichuan Agricultural University, China.

\section{RNA isolation and CDNA synthesis}

The frozen skin tissues were ground using mortars in liquid nitrogen and the total RNA was isolated by Trizol reagent (Invitrogen, Carlsbad CA, USA) according to the manufacturer's protocols. The concentration and quality of the total RNA were further assessed using the NanoDrop spectrophotometer (Bio-Rad, Benicia, USA). The RNase-free DNase I (Promega, Madison, USA) was used to digest genomic DNA. The first-strand cDNA was synthesized using the M-MLV reverse transcriptase kit (Promega, Madison, USA) with oligo (dT) primer.

\section{Gene cloning and quantitative PCR analysis}

Three primer pairs were designed to amplify the caprine $T R \alpha$ and CRABPII genes according to their conserved regions of homologies from human, mouse, cattle, sheep and pig (Table 1). PCR was carried out in a $25 \mu \mathrm{L}$ reaction mixture containing $2 \mu \mathrm{L}$ first-strand cDNA, $50 \mathrm{mM} \mathrm{KCl}, 10 \mathrm{mM}$ Tris- $\mathrm{HCl}(\mathrm{pH}$ 8.3), $0.5 \mathrm{mM} \mathrm{MgCl} 2$, 10 pmol each primer, $150 \mu \mathrm{M}$ dNTPs and 1 unit Taq polymerase (TaKaRa, Dalian, China). The cycling condition included an initial denaturation step at $95{ }^{\circ} \mathrm{C}$ for $5 \mathrm{~min}, 38$ cycles of at $94{ }^{\circ} \mathrm{C}$ for $30 \mathrm{~s}$, annealing temperature for $30 \mathrm{~s}$ and extension at $72{ }^{\circ} \mathrm{C}$ for $45 \mathrm{~s}$, and a final extension at $72{ }^{\circ} \mathrm{C}$ for
7 min in a PTC-100 PCR thermocycler (MJ Research, Inc., Watertown, MA). PCR products were ligated with the pMD19-T vector (TaKaRa, Dalian, China) after purification, and sequenced by Invitrogen Biotech Co. Ltd. (Shanghai, China).

The quantitative PCR (qRT-PCR) was carried out in an iCycler iQ Real-Time PCR Detection System (BioRad, Benicia, USA) with a total volume of $20 \mu \mathrm{L}$ containing $10 \mu \mathrm{L} 2 \times$ SYBR Premix Ex Taq II, $0.6 \mu \mathrm{L}$ primers $(10 \mu \mathrm{M})$ and $1 \mu \mathrm{L}$ diluted cDNA. PCR reaction was as follows: a $95{ }^{\circ} \mathrm{C}$ denaturation for $30 \mathrm{~s}$, followed by 40 cycles of $94{ }^{\circ} \mathrm{C}$ for $15 \mathrm{~s}$, annealing temperature for $30 \mathrm{~s}$, and $72{ }^{\circ} \mathrm{C}$ for $30 \mathrm{~s}$. A melting program ranging from $55{ }^{\circ} \mathrm{C}$ to $95{ }^{\circ} \mathrm{C}$ with a heating rate of $0.5^{\circ} \mathrm{C} / 10 \mathrm{~s}$ was carried out to create the melt curves. Reactions were performed in triplicate and negative control was also performed in parallel.

\section{Normalization of the expression data}

In the present study, three internal control genes ( $A C T B, G A P D H$ and $T O P 2 B$, Table 1) were selected to normalize the expression levels of $T R \alpha$ and CRABPII mRNAs. To accurate expression profiling of target genes, the geometric mean of multiple carefully selected housekeeping genes was validated as an accurate normalization factor [24]. The relative gene expression was calculated with the $2^{-\Delta \Delta C t}$ method [25]. Data were presented as mean $\pm \mathrm{SE}$. Comparisons between groups were analyzed via GLM (General Linear Model) for experiments with more than 2 subgroups. The significance level was $P<0.05$. 

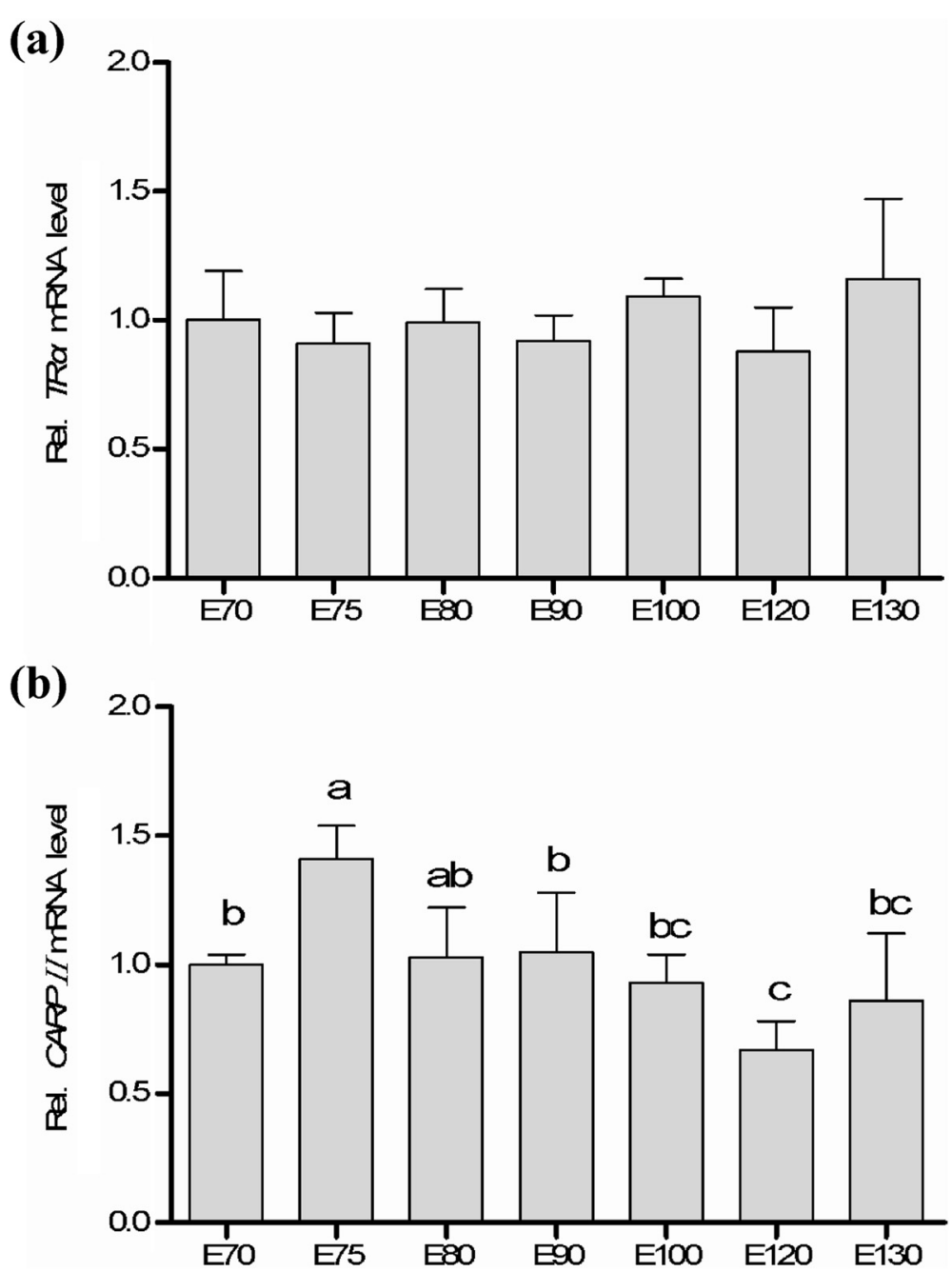

Fig. 3 The quantitative expressions of TRa (a) and CRABPII mRNAs (b) in skin tissue of Inner Mongolian Cashmere goat. The bar height presented the means, and error bar displayed +1SE $(n=3)$. Different letters above the bars indicate a significant difference $(P<0.05)$ between different stages

\section{Results and discussion}

Characteristics of goat TRa and CRABPII mRNAs

A 1,309-bp fragment of TR $\alpha$ was assembled by the two overlapped sequences of $T R \alpha-1 \mathrm{~F} / 1 \mathrm{R}$ and $T R \alpha-2 \mathrm{~F} / 2 \mathrm{R}$ with an open reading frame (ORF) extending from nucleotide positions 21 to 1,253 (with reference to the translational start codon of ATG), which encoded a protein with 410 amino acids (Accession No. KF589923). The obtained sequence of CRABPII mRNA was $563 \mathrm{bp}$ in length with an ORF of 417 bp encoding 138 amino acids (Accession No. KF589924). The blast results revealed that both of $T R \alpha$ and CRABPII were quite conserved among species (Fig. 1, Additional file 1: Figure S1 and Additional file 2: Figure S2). The sequence similarity ranged from $88 \%$ to $100 \%$ (Additional file 3: Table S1). The coding sequence of the caprine TR $\alpha$ gene shows a high similarity with the sequences in other mammals, sharing $99 \%$ identity with sheep (NM_001100919) and cattle (NM_001046329). The goat CRABPII shows $88 \%$ identity with mice (NM 007759) and $98 \%$ identity with cattle (NM_001008670).

The nucleotide sequences were aligned by the Cluster W method included in the program BioEdit version 7.2.5 [26]. The phylogenetic analysis was constructed using the program MEGA 4.1 [27], with a Kimura 2-parameter model and a bootstrap test (1000 replications). The phylogenetic tree revealed that the goat $T R$ grouped with sheep, and then clustered with cattle, pig, human, mice and chicken subsequently (Fig. 2a). The phylogenetic tree of CRABPII gene showed a similar clustering with differences in sort of branch-length groups (Fig. 2b). The Minimum Evolution, Maximum Parsimony and UPGMA trees revealed the same clustering groups as presented by the NJ trees (data not shown). 
Time-course expressions of $T R a$ and CRABPII genes

To better understand the prenatal dynamical expressions of TR $\alpha$ and CRABPII in the skin tissue of cashmere goats, the qRT-PCR array was performed in the middle late embryonic stages (E70 to E130). As shown in Fig. 3, both of TR $\alpha$ and CRABPII mRNAs were detectable in all the tested time points. However, no significant difference of $T R \alpha$ gene expression was detected during the middle late development of goat embryos. The mRNA of $T R \alpha$ was expressed at E70 with relatively high level and mildly decreased in the following three stages (E75, E80, and E90), and then increased at E100 and reduced to the lowest level at E120, subsequently. The highest expression of $T R \alpha$ gene was observed in the last stage $(E 130, P>0.05)$. The previous studies has reported that the secondary follicles grew from E65 to E75 and then extended to skin surface. The complete structure of the secondary follicle was formed at E135 in Chinese cashmere goats [4, 28, 29]. Synchronously coupled with the early formation and growth of cashmere, the mRNA expression of $T R \alpha$ gene was upregulated indicating that $T R \alpha$ could play a role in the time-course growth of goat cashmere.

The expression pattern of CRABPII mRNA showed an "up-down-up" trend, which revealed a significantly highest expression at E75 $(P<0.05)$, and was downregulated during E80 to E120 $(P<0.05)$ then increased again at E130. In embryonic development of hair follicles, the glandula sebacea cells were observed in the skin tissue from cashmere goat fetus at E85 [30]. The glandula sebacea formed at E90 and accelerated the growth of primary hair follicles. However, the physiologic difference between primary and secondary follicles was that no glandula sebacea was found in secondary hair follicles. The second hair follicles grew retard and partially matured at E130. The mRNA expression of CRABPII at E90 was lower than that at E80 when no glandula sebacea was formed. The CRABPII gene could regulate the early development of glandula sebacea though modifying the concentration of RA. The mRNA of CRABPII gene at E100 expressed significantly higher than that at E120, which led more RA transported into nucleus and bound to its receptor, and proposed to boost the growth of glandula sebacea. In humans, the concentration of RA in cells could increase the mRNA expression of CRABPII in skin $[31,32]$.

In this study, we characterized the caprine $T R \alpha$ and CRABPII genes and quantified their mRNA expressions during the formation of secondary hair follicles in the middle late embryonic periods. Our study will enrich the knowledge of goat TR $\alpha$ and CRABPII genes and provide the foundation for further insight into their functions on cashmere growth.

\section{Conclusions}

Cashmere wool is the very valuable production obtained from goats. It is very important to investigate the expressions of key functional genes associated with cashmere growth during the prenatal and process-oriented periods (from anagen to catagen and finally telogen). Taken together, our results profiled the expressions of TR $\alpha$ and CRABPII genes associated with prenatal development of goat hair follicle.

\section{Additional files}

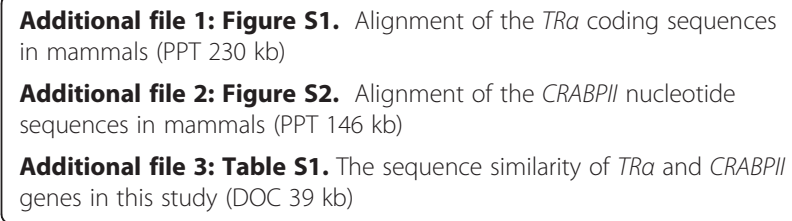

Additional file 2: Figure S2. Alignment of the CRABP/l nucleotide sequences in mammals (PPT $146 \mathrm{~kb}$ )

Additional file 3: Table S1. The sequence similarity of TRa and CRABPII genes in this study (DOC $39 \mathrm{~kb}$ )

\section{Competing interests}

The authors declare that they have no competing interests.

\section{Authors' contributions}

HPZ and HL designed experiment, TZ, WZ and ZQZ conducted experiment, LL and LW analyzed data, TZ and WZ written manuscript. All authors read and approved the final manuscript.

\section{Acknowledgements}

This study was supported by the Chinese Domestic Animal Germplasm Resources Infrastructure, the Technology Support Program of Sichuan province (2011NZ0099-36) and the National Transgenic Project (2011ZX08008002).

Received: 12 April 2015 Accepted: 6 August 2015

Published online: 20 August 2015

\section{References}

1. Mou C, Jackson B, Schneider P, Overbeek PA, Headon DJ. Generation of the primary hair follicle pattern. Proc Natl Acad Sci U S A. 2006;103:9075-80.

2. Cadau S, Rosignoli C, Rhetore S, Voegel J, Parenteau-Bareil R, Berthod F. Early stages of hair follicle development: a step by step microarray identity. Eur J Dermatol. 2013. doi:10.1684/ejd.2013.1972.

3. Zhang JY, Yin J, Li JQ, Li CQ. Study on hair follicle structure and morphogenesis of the Inner Mongolian Arbas cashmere goat. Sci Agric Sin. 2007;40:1017-23.

4. Li YR, Fan WB, Li CQ, Yin J, Zhang JY, Li JQ. Histomorphology research of the secondary follicle cycling of Inner Mongolia cashmere goat. Sci Agric Sin. 2008:41:3920-6.

5. Li CQ, Yin J, Zhang HY, Guo ZC, Zhang WG, Gao AQ, et al. Comparative study on skin and hair follicles cycling between Inner Mongolia and Liaoning cashmere goats. Acta Veterinariaet Zootechnica Sinica. 2005;36:674-9.

6. Parry AL, Norton BW, Restall BJ. Skin follicle development in the Australian cashmere goat. Aust J Agr Res. 1992;43:857-70.

7. Stenn KS, Paus R. Controls of hair follicle cycling. Physiol Rev. 2001;81:449-94.

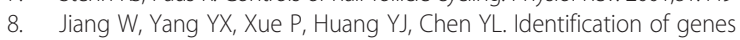
preferentially expressed in goat hair follicle anagen-catagen transition using suppression subtractive hybridization. Anim Biotechnol. 2012;23:11-23.

9. Jin M, Wang L, Li S, Xing MX, Zhang X. Characterization and expression analysis of KAP7.1, KAP8.2 gene in Liaoning new-breeding cashmere goat hair follicle. Mol Biol Rep. 2011;38:3023-8.

10. Wang X, Zhao ZD, Xu HR, Qu L, Zhao HB, Li T, et al. Variation and expression of KAP9.2 gene affecting cashmere trait in goats. Mol Biol Rep. 2012;39:10525-9. 
11. Su R, Li JQ, Zhang WG, Yin J, Zhao J, Chang ZL. Expression of BMP2 in the Skin and Hair Follicle from Different Stage in Inner Mongolia Cashmere Goat. Sci Agric Sin. 2008;41:559-63.

12. Bai $W L$, Yin $R H$, Jiang $W Q$, Luo GB, Yin RL, Li C, et al. Molecular characterization of prolactin CDNA and its expression pattern in skin tissue of Liaoning Cashmere goat. Biochem Genet. 2012:50:694-701.

13. Seki Y, Yokohama M, Wada K, Fujita M, Kotani M, Nagura Y, et al. Expression analysis of the type I keratin protein keratin 33A in goat coat hair. Anim Sci J. 2011;82:773-81.

14. Shah RM, Ganai TA, Sheikh FD, Shanaz S, Shabir M, Khan HM. Characterization and polymorphism of keratin associated protein 1.4 gene in goats. Gene. 2013;518:431-42.

15. Safer JD. Thyroid hormone action on skin. Curr Opin Endocrinol Diabetes Obes. 2012;19:388-93.

16. van Beek N, Bodo E, Kromminga A, Gaspar E, Meyer K, Zmijewski MA, et al. Thyroid hormones directly alter human hair follicle functions: anagen prolongation and stimulation of both hair matrix keratinocyte proliferation and hair pigmentation. J Clin Endocrinol Metab. 2008;93:4381-8.

17. Villar D, Nicol F, Arthur JR, Dicks P. P, Cannavan A, Kennedy DG, et al. Type II and type III monodeiodinase activities in the skin of untreated and propylthiouracil-treated cashmere goats. Res Vet Sci. 2000;68:119-23.

18. Rhind SM, Kyle CE. Skin deiodinase profiles and associated patterns of hair follicle activity in cashmere goats of contrasting genotypes. Aust J Agr Res. 2004:55:443-8

19. Torma H, Karlsson T, Michaelsson G, Rollman O, Vahlquist A. Decreased mRNA levels of retinoic acid receptor alpha, retinoid $X$ receptor alpha and thyroid hormone receptor alpha in lesional psoriatic skin. Acta Derm Venereol. 2000:80:4-9.

20. Moeller LC, Cao X, Dumitrescu AM, Seo H, Refetoff S. Thyroid hormone mediated changes in gene expression can be initiated by cytosolic action of the thyroid hormone receptor $\beta$ through the phosphatidylinositol 3-kinase pathway. Nucl Recept Signal. 2006;4, e020.

21. Everts $H B$, Sundberg JP, King Jr LE, Ong DE. Immunolocalization of enzymes, binding proteins, and receptors sufficient for retinoic acid synthesis and signaling during the hair cycle. J Invest Dermatol. 2007;127:1593-604.

22. Sessler RJ, Noy N. A ligand-activated nuclear localization signal in cellular retinoic acid binding protein-II. Mol Cell. 2005;18:343-53.

23. Everts $H B$, King Jr LE, Sundberg JP, Ong DE. Hair cycle-specific immunolocalization of retinoic acid synthesizing enzymes Aldh1a2 and Aldh1a3 indicate complex regulation. J Invest Dermatol. 2004;123:258-63.

24. Vandesompele J, De Preter K, Pattyn F, Poppe B, Van Roy N, De Paepe A, et al. Accurate normalization of real-time quantitative RT-PCR data by geometric averaging of multiple internal control genes. Genome Biol. 2002;3:research0034.

25. Livak KJ, Schmittgen TD. Analysis of relative gene expression data using real-time quantitative $P C R$ and the 2(-Delta Delta C(T)) Method. Methods. 2001;25:402-8

26. Hall TA. BioEdit: a user-friendly biological sequence alignment editor and analysis program for Windows 95/98/NT. Nucl Acids Symp Ser. 1999;41:95-8.

27. Tamura K, Dudley J, Nei M, Kumar S. MEGA4: Molecular Evolutionary Genetics Analysis (MEGA) software version 4.0. Mol Biol Evol. 2007;24:1596-9.

28. Wang $L$, Peng $L$, Zhang W, Zhang J, Yang W, Ding $L$, et al. Initiation and development of skin follicles in the Inner Mongolian cashmere goat. Acta Veterinariaet Zootechnica Sinica. 1996;27:524-30.

29. Zhang JX, Wang L, Yin J, Li JQ, Zhang HJ. Expression of KAP6 gene family on the skin of fetal goat. Animal Husbandry and Feed Science. 2009;30:20-1.

30. Zhang YJ, Li CQ, Li JQ. Study on Development of Skin and Hair Follicle from Fetal Inner Mongolian Arbas Cashmere Goats. Acta Veterinariaet Zootechnica Sinica. 2006:37:761-8.

31. Astrom A, Tavakkol A, Pettersson U, Cromie M, Elder JT, Voorhees J J. Molecular cloning of two human cellular retinoic acid-binding proteins (CRABP). Retinoic acid-induced expression of CRABP-II but not CRABP-I in adult human skin in vivo and in skin fibroblasts in vitro. J Biol Chem. 1991;266:17662-6.

32. Millar SE. Molecular mechanisms regulating hair follicle development. J Invest Dermatol. 2002;118:216-25.

\section{Submit your next manuscript to BioMed Central and take full advantage of:}

- Convenient online submission

- Thorough peer review

- No space constraints or color figure charges

- Immediate publication on acceptance

- Inclusion in PubMed, CAS, Scopus and Google Scholar

- Research which is freely available for redistribution

Submit your manuscript at www.biomedcentral.com/submit 